\title{
Incidence and Predictors of Pulmonary Tuberculosis among Children Who Received Antiretroviral Therapy (ART), Northwest Ethiopia: A Multicenter Historical Cohorts Study 2009-2019
}

\author{
Fassikaw Kebede $\mathbb{D}^{1},{ }^{1}$ Habtamu Tarekegn, ${ }^{2}$ Mulugeta Molla $\mathbb{D}^{\mathrm{D}},{ }^{3}$ Dube Jara $\mathbb{i},{ }^{4}$ \\ and Abebe Abate $\mathbb{B D}^{4}$ \\ ${ }^{1}$ Woldia University, College of Health Sciences, School Public Health, Department of Epidemiology \& Biostatics, Woldia, Ethiopia \\ ${ }^{2}$ Pawe Health Science College, Department of Pharmacy, Pawe Metekel, Ethiopia \\ ${ }^{3}$ Debre Tabor University, College of Medicine and Health Science, Department of Pharmacy, Debre Tabor, Ethiopia \\ ${ }^{4}$ Debre Markose University, College of Medicine and Health Science, Department of Public Health, Debra Markose, Ethiopia
}

Correspondence should be addressed to Fassikaw Kebede; fassikaw123@gmail.com

Received 8 September 2021; Revised 28 December 2021; Accepted 8 January 2022; Published 28 January 2022

Academic Editor: Maoshui Wang

Copyright $\odot 2022$ Fassikaw Kebede et al. This is an open access article distributed under the Creative Commons Attribution License, which permits unrestricted use, distribution, and reproduction in any medium, provided the original work is properly cited.

\begin{abstract}
The human immune deficiency virus (HIV) is the strongest risk factor for endogenous reactivation of pulmonary tuberculosis (PTB) through target reduction of CD4, T-lymphocytes, and cellular immune function. Almost one-third of deaths among people living with HIV are attributed to tuberculosis. Despite this evidence, in Ethiopia, information is scarce and meager regarding PTB incidence after ART initiated for seropositive children. Methods. Facility-based multicenter historical cohort was conducted among 721 seropositive children after initiating ART from January 1, 2009, to December 31, 2019. Data from the records of children were extracted using a standardized checklist. The collected data were entered using Epi-Data version 4.2 and exported to STATA (SE) R-14 version statistical soft wares for further analysis. Bivariable and multivariable Cox regression analyses were conducted to identify predictors of PTB incidence. Results. Seven hundred twenty-one $(N=721)$ seropositive children were included with a mean $( \pm S D)$ age of $118.4 \pm 38.24$ months. During the follow-up periods, $63(15.2 \%)$ participants developed new cases of TB; majority $(61 / 63,96.8 \%)$ of them were PTB. The overall incidence rate and the median $( \pm \mathrm{IQR})$ time of PTB reported were determined as 5.86 per 100 child years $(95 \%$ CI: $4.58,7.5)$ and $17.8( \pm 11)$ months, respectively. At baseline, children being severely stunted $(\mathrm{AHR}=2.9: 95 \% \mathrm{CI}, 1.2-7.8, P=0.03)$, with $\mathrm{Hgb} \leq 10 \mathrm{mg} / \mathrm{dl}(\mathrm{AHR}=4.0 ; 95 \% \mathrm{CI}, 2.1-8.1, P=0.001)$, and not given isoniazid and cotrimoxazole preventive therapy $(\mathrm{AHR}=2.4 ; 95 \% \mathrm{CI}$ : 1.2; 5.1, $P=0.001)(\mathrm{AHR}=2.5 ; 95 \% \mathrm{CI}, 1.4-4.7$, $P=0.021)$ were significantly associated with PTB incidence. Conclusion. A high incidence rate of PTB was observed in our study as compared with the previous finding in Ethiopia. Cases at baseline not taking IPT and CPT, being severely stunted, and having low hemoglobin $(\leq 10 \mathrm{mg} / \mathrm{dl})$ levels were found to be at higher risk of developing PTB.
\end{abstract}

\section{Introduction}

The human immune deficiency virus (HIV) is the strongest risk factor for latent $(\mathrm{PTB})$ or new infection of tuberculosis (TB) through reduction of CD4 T-lymphocytes and cellular immune function [1]. Despite this fact, both (TB/HIV) coinfections are bidirectional and comrade each other, in which HIV sustains the progression of latent tuberculosis bacilli into active TB, while tuberculosis accelerates the progression of HIV disease stages [2]. This coexistence of PTB and HIV infection increased the risk of morbidity and mortality. ART has decreased TB incidence in HIV-infected patients [3]. The waning of the immune system increased Mycobacterium tuberculosis susceptibility and progression of dormant tuberculosis bacilli to endogenous reactivation of latent incidence in the lung [4]. Pulmonary complications have been one of the commonest causes of morbidity and 
mortality since the advent of the AIDS pandemic and this further led to the parallel pandemic of tuberculosis in some sub-Saharan African populations where 10\%-15\% suffered from multiple infections [2,5]. According to the World Health Organization (WHO) report, in 2019, there were an estimated 10.1 million new cases of TB and 1.7 million new deaths, making TB the leading cause of death from a single infectious agent (ranking above HIV/AIDS) [6]. The reactivation of latent pulmonary $\mathrm{TB}$ is higher among people living with HIV. Africa is the second TB burden region (25\%) after Southeast Asia $(44 \%)[6,7]$ and is responsible for one-third of TB/HIV-associated deaths of children living with HIV $[8,9]$.

Globally, about 36.7 million patients were living with HIV/AIDS and 2.1 million people became newly infected in 2015. Sub-Saharan Africa countries account for the largest proportion, with 25.6 million people living with HIV [1, 6]. Likewise, in 2018, there were about 251,000 deaths from TB among PLWHIV, which accounts for $33 \%$ of total deaths associated with HIV, which is much higher than the case fatality rate expected $\leq 5 \%$ by WHO $[1,10]$.

People living with HIV (PLWHIV) who have active TB disease were prone to several adverse outcomes. In particular, seropositive children have the risk of increased mortality, developing AIDS-defining event, and loss to follow uprate [7]. The Ethiopian Federal HIV and AIDS Prevention and Control Office estimated that the single National HIV/AIDS is among the top ten high burden counties, in which $31 \%$ of TB patients are living with HIV $[9,10]$. Physiologically, lack of productive cough and sputum for children living with HIV deters early diagnosing and treatment of HIV-associated PTB $[11,12]$. Epidemiological data on the magnitude of PTB comorbidity is important to control and prevent both diseases. In this regard, facility-based studies conducted in Ethiopia have indicated that HIV-associated PTB has an increasing trend from $5.0 \%$ in Northern Ethiopia [2] to $7.2 \%$ in Southwest Ethiopia [5]. Additional studies are required in different regions of Ethiopia to identify highrisk children's cases management. Therefore, this study was intended to estimate magnitude and predictors for the occurrence of pulmonary $\mathrm{TB}$ among children who received antiretroviral therapy in 2020 .

\section{Methods}

2.1. Study Design, Area, and Populations. Metekel zone is one of the three administrative zones found in the Benishangul Gumuz region in Northwest Ethiopia, geographically located within $34^{\circ} 10^{\prime} \mathrm{N}$ and $37^{\circ} 40^{\prime} \mathrm{E}$ and latitude $09^{\circ} 17^{\prime} \mathrm{N}$ and $12^{\circ} 06^{\prime} \mathrm{N}$. This zone had seven administrative district Woredas with two primary and one-referral hospitals. Gilgel Belles is the capital of Metekel zone, which is located at 565 and $394 \mathrm{~km}$ away from Addis Ababa and Assosa, on the way to GERD projects (Ethiopian Great Renaissance Damp at Abay River). Apart from other health service, all these health institutions have been providing ART care services since $2007[4,13]$.
2.2. Study Design. A facility-based historical cohort study design was employed among 721 seropositive children in two hospitals and two health centers from January 1, 2009, to December 31, 2019. All these health facilities provide health care services for an estimated 2968 total catchment populations as depicted in $[4,14]$ Figure 1.

2.3. Study Populations. All recoded pediatrics patients under the age of 15 years who received ART initiated and started care in four selected public health facilities were considered as source population. All HIV-infected children who had at least one month of ART follow-up from January 1, 2009, to December 31, 2019, were included. Patients taking anti-TB treatment at the time of HIV/AIDS enrolment were excluded from the study.

\subsection{Sample Size Determination and Sampling Techniques.} The sample size was calculated by using the formula for survival analysis considering the following parameters, twosided significance level $(\alpha=5 \%), Z a / 2=Z$ value at $95 \%$ confidence interval $=1.96$, power $\left(Z_{B}\right)=80 \%$, and $\mathrm{AHR}=$ adjusted hazard ration $=1.8[14]$.

The final sample size $(n)=$ Event $/ P$ (Event $)=\left(Z_{a / 2}+\right.$ $\left.Z_{B}\right) 2 / \theta^{2} p(1-p)=(z a / 2+Z B) / p(1-p)(\ln \mathrm{HR}) 2[15]$.

$$
\begin{aligned}
\theta & =\ln (\mathrm{HR}), \\
\mathrm{HR} & =e^{\theta},
\end{aligned}
$$

where alpha $(a)=0.05$, beta $(\beta)=0.2$, AHR is hazard ratio, $E$ is number of events, $N$ (sample size $)=E / P(E)$, where $P(E)=$ probability of event, and $P=$ cumulative occurrence of pulmonary $\mathrm{TB}, 7.2 \%$ from this reference [5]. The final sample size was determined as 512.5 after adding $15 \%$ contingency for data incompleteness. However, from 1, 2009, to December 31, 2019. Totally, 738 charts were found within the four institutions. Since this data is manageable in resources and could have been assumed to the increased power of inference, we included all charts without sampling procedure.

2.5. Outcome Ascertainment. The PTB incidence is considered as an event of interest after HIV/AIDS care clinic started. Children who were lost, died, or transferred out or did not develop the events until the last visit were considered censored, whereas variables including sociodemographic such as age, sex, residence, family size, parental history of TB contact, plus clinical factors like WHO clinical stage, baseline cluster of differentiation (CD4 count), Hgb, functional status, and nutritional status like stunting, wasting, and being underweight were considered as independent variables.

2.6. Operational Words. Smear-positive pulmonary tuberculosis: at least one sputum smear examination is positive for AFB on direct-microscopy. Smear-negative pulmonary tuberculosis: sputum specimens negative for $\mathrm{AFB}$ and radiographical abnormalities were consistent with active TB 


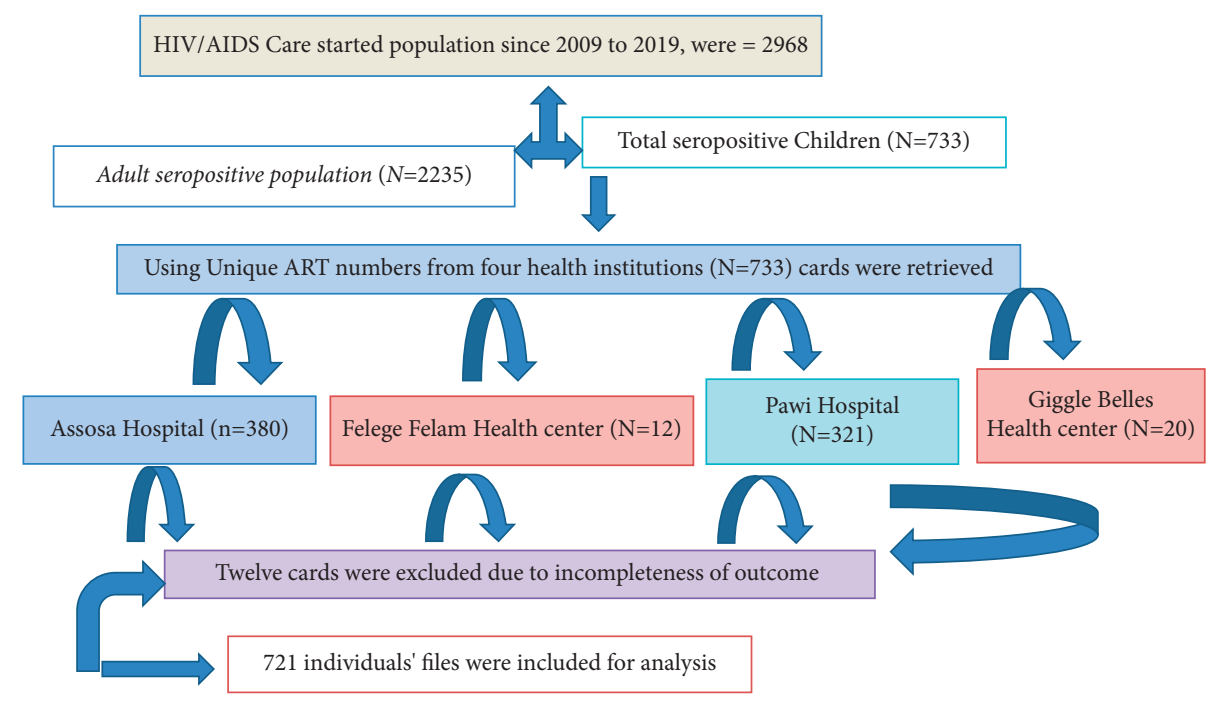

FIGURE 1: Schematic presentation sampling procedures for the study of seropositive children.

and the decision by a clinician to treat with a full course of antituberculosis chemotherapy. Extrapulmonary tuberculosis is clinically consistent with active extra-pulmonary TB and bacteriologically confirmed by AFB of one specimen from an extrapulmonary site for Mycobacterium tuberculosis and a decision by a clinician to treat with a full course of antiTB chemotherapy [1].

2.7. Operational Words. SAM DefinitionAccording to the $\mathrm{WHO}$, weight-for-height $\leq-3 \mathrm{Z}$-score, or mid-upper-arm circumference $<115 \mathrm{~mm}$, or presence of bilateral edema with failed appetite test should be classified for inpatient care [16]. Undernutrition was defined as a child having one of the description $\mathrm{H} /$ Age Z-score $<-2$ or W/Age Z-score $<-2$ or $\mathrm{W} / \mathrm{H} \mathrm{Z}$-score $<-2 \mathrm{SD}[17,18]$. Moreover, the details description is here below as moderate underweight was defined as children having W/Age Z-score $<-2$ SD or severe was defined as children; moderate stunting was defined as children having $\mathrm{H} /$ Age $\mathrm{Z}$-score $<-2 \mathrm{SD}$. Severe stunting was defined as children having $\mathrm{H} /$ Age $\mathrm{Z}$-score $<-3 \mathrm{SD}[18,19]$. Moderate wasting was defined as children having $\mathrm{W} / \mathrm{H}$ Z-score $<-2 \mathrm{SD}$. Severe wasting was defined as children having $\mathrm{W} / \mathrm{H} \mathrm{Z}$-score $<-3 \mathrm{SD} n$ having $\mathrm{W} /$ Age $\mathrm{Z}$-score $<-3$ $Z$ score $[17,18]$.

A CD4 Count CD4 below the threshold level was classified based on the age of the child's (i.e., infants CD $4<1500 / \mathrm{mm} 3, \quad 12-35$ months $<750 / \mathrm{mm} 3, \quad 36-59$ months $<350 / \mathrm{mm} 3$, and $\geq 5$ years $<200 / \mathrm{mm} 3$ ) [10]. ART Adherence for pediatrics is classified based on the percentage of drug dosage calculated from the total monthly doses of ART drugs; Good $>95 \%$, fair $85-94 \%$, and poor $<85 \%$. Seropositive children: According to FMOH Continuum of HIV services refers to a comprehensive package of HIV prevention, diagnostic, treatment, care, and support services provided for people at risk of HIV infection or living with HIV and their families" children aged $<15$ years were classified and treated seropositive children $[10,20]$.

2.8. Data Collection Instruments. A standard and pretested data extraction form was used to extract the required information from Ethiopia's Federal Ministry of Health Pediatrics antiretroviral therapy (ART) follow-up [11]. Before the actual data collection, the prepared checklists were pretested on 36 case notes of follow-up in seropositive children from Jawi Hospital. The two-day training was given for six-diploma nurse's data collectors and two-degree public health officers of supervisors on the objective of the study, variables of interest, and maintaining data confidentiality. Strict follow-up and supervision were carried out during data collection by the principal investigators and feedback was given on daily basis. The collected data were checked for inconsistencies, coding errors, completeness, accuracy, and missing values.

2.9. Data Collection Procedures and Quality Assurance. To assure the quality of data, data collectors and supervisors were trained about how and what information they should collect from the medical records for one day. The checklist was pretested on $5 \%$ of randomly selected charts, which were not included in the actual study. After the pretest, necessary modification of the data collection tool was made. Strict follow-up and supervision were carried out during data collection by principal investigators and feedback was given daily. Individual records with incomplete data during data collection were excluded. The collected data were first being checked and cleaned for completeness.

2.10. Statistical Analyses. Data were entered using Epi-Data version 4.2 statistical software and exported to STATA (SE) $\mathrm{R}-14$ version statistical software for further analysis. The WHO AntroPlus Version 1.04 and ENA for Smart Software was used 
TABLE 1: Baseline sociodemographic characteristic of HIV positive children who received ART in selected public health facility, Northwest Ethiopia, $2020(N=721)$.

\begin{tabular}{|c|c|c|c|}
\hline Variables & Categories & Frequency & Percent \\
\hline \multirow{2}{*}{ Sex } & Male & 337 & 46.7 \\
\hline & Female & 384 & 53.3 \\
\hline \multirow{3}{*}{ Age of children } & $\geq 5$ years & 78 & 10.8 \\
\hline & $6-10$ & 254 & 35.2 \\
\hline & $11-15$ years & 389 & 53.9 \\
\hline \multirow{2}{*}{$\begin{array}{l}\text { HIV disclosure status of } \\
\text { children }\end{array}$} & Disclosed & 158 & 21.9 \\
\hline & Not disclosed & 563 & 78.1 \\
\hline \multirow{2}{*}{ Age of caregivers } & $\leq 45$ years & 244 & 38.8 \\
\hline & $<45$ years & 477 & 66.1 \\
\hline \multirow{3}{*}{ Resident } & Urban & 510 & 70.8 \\
\hline & Rural & 211 & 29.3 \\
\hline & Single & 115 & 15.9 \\
\hline \multirow{4}{*}{$\begin{array}{l}\text { Marital status of the } \\
\text { caregiver }\end{array}$} & Married & 498 & 69.1 \\
\hline & Divorced & 82 & 11.4 \\
\hline & Widowed & 26 & 3.6 \\
\hline & $\leq 2$ & 227 & 31.4 \\
\hline \multirow[t]{3}{*}{ Family size of caregivers } & $3-5$ & 462 & 64.1 \\
\hline & $\geq 6$ & 32 & 4.4 \\
\hline & Positive & 550 & 76.3 \\
\hline \multirow[t]{3}{*}{ HIV status of caregivers } & Negative & 91 & 12.6 \\
\hline & Unknown & 80 & 11.1 \\
\hline & Orthodox & 381 & 52.8 \\
\hline \multirow{4}{*}{ Religions of caregivers } & Muslim & 152 & 21.2 \\
\hline & Protestant & 139 & 19.3 \\
\hline & Catholics & 49 & 6.8 \\
\hline & Farmer & 99 & 13.7 \\
\hline \multirow{3}{*}{$\begin{array}{l}\text { Occupational status of } \\
\text { caregivers }\end{array}$} & Merchant & 337 & 46.7 \\
\hline & Employer & 124 & 17.2 \\
\hline & $\begin{array}{l}\text { Laborer } \\
\text { worker }\end{array}$ & 161 & 22.3 \\
\hline \multirow{4}{*}{$\begin{array}{l}\text { Parental status of care } \\
\text { children }\end{array}$} & Both alive & 381 & 52.8 \\
\hline & $\begin{array}{l}\text { Paternal } \\
\text { orphan }\end{array}$ & 135 & 18.2 \\
\hline & $\begin{array}{l}\text { Maternal } \\
\text { orphan }\end{array}$ & 108 & 14.9 \\
\hline & Both orphaned & 97 & 13.5 \\
\hline
\end{tabular}

to generate the $Z$ score ( $W A Z, H A Z, W H Z / B A Z$ ) to define the nutritional status of seropositive children. We used the Cox regression hazards, regression model, to estimate mortality incidence and predictors during risky successive follow-up. Kaplan-Meier survival analysis was used to determine the cumulative probability of death for all seropositive children and the meantime to death. Variable with $P$ value $<0.25$ in bivariable Cox regression analysis was included in the multivariable Cox regression model. We tested the assumptions of Cox Proportional Hazard Models using Schoenfeld residuals. Variables with an AHR and 95\% confidence interval (CI) and a $P$ value $<0.05$ were claimed as significant predictors SAM associated mortality of seropositive children.

\section{Result}

3.1. Sociodemographic Characteristics of Seropositive Children. As depicted in Figure 1, data of seven hundred thirty-two $(N=732)$ seropositive children who initiated ART care were reviewed. During the data extraction process,
12 pediatrics files were excluded due to previous TB treatment and incomplete documentation. Based on this, the overall response rate found was $721 / 732$ (99.6\%). More than half $(384,53.26 \%)$ of participant cases were females in gender, and $510(70.74 \%)$ of them were from urban areas. The largest percentage of participant cases was categorized under the age group 11-15 years, which accounted for 389 (53.96\%) of the total subjects. The overall mean ( \pm SD) age of participant children was found to be $118.4 \pm 38.24$ months (Table 1).

3.2. Clinical and Medication Characteristics. From the total 721 participant children, more than one-third $(258,35.78 \%)$ of cases had at least one type of opportunistic infection (OI). The most frequent OIs (107 (41.47\%) and 100 (38.7\%)) were diarrheal disease and bacterial pneumonia, respectively.

Moreover, slightly less than half $(293,40.64 \%)$ of cases were on AZT-3TC-NVP of ART regimen. Of the total, 237 (33.1\%) and $202(28.02 \%)$ participant children were on WHO stage I \& II. More than half $(419,58.2 \%)$ of participant cases addressed cotrimoxazole preventive therapy (CPT) (Table 2).

3.3. Baseline Nutritional Characteristics. Of the total 721 seropositive children nutritionally, $16.6 \%, 19.9 \%$, and $21.4 \%$ were moderately wasted, underweight, and stunted, respectively. Nearly, one-in-five $(124,17.2 \%)$ of cases had an inpatient admission history for severe acute malnutrition (SAM) treatment (Table 3).

3.4. Incidence of Pulmonary TB. About 721 participants' children were followed up for 16678.07 person per month risk of observation. During the follow-up period, $8.79 \%$ ( $n=63$ ) of new cases of TB occurred. The majority, $52.4 \%$ $(N=36 / 63)$ vs. $38.2 \%(n=25 / 63)$ cases, were smear negative and smear positive pulmonary TB as documented, respectively. However, the remaining $3.4 \%(n=2)$ of cases were extrapulmonary TB (EXPTB). Regarding clinical presentations of SNPTB cases, $27(72.7 \%)$ and 23 (60.6\%) had a history of high-grade fever and night sweating, respectively. The overall incidence of PTB in this study was determined as 5.8 per 100 child years ( $95 \% \mathrm{CI}: 4.58,7.5)$. In addition, the incidence of those two new TB cases was estimated as 0.21 per 100 child years risks of observations (Table 4).

3.5. Predictors for Incidence of PTB. As shown in Table 5 in the multivariable Cox regression analysis, after adjustment and controlling of certain confounding in the final model, four variables were found significantly associated with PTB incidence. Based on this, the risks of developing PTB for children who were not given CPT were more than two times increased as compared with those who were addressed CPT at baseline $(\mathrm{AHR}=2.5$ : 95\% CI, 1.84-4.74, $P<0.021)$. Likewise, the risks of developing PTB infection for seropositive children being nutritionally curved height for age (HFA) $\leq-3 Z$ score) or being severely stunted were three times $(\mathrm{AHR}=2.9$ : 95\% CI, 1.2-7.8, $P<0.03)$ higher as 
TABLE 2: Clinical and hematologic characteristics of seropositive children attending ART care in selected public health facilities $(N=721)$, 2020 .

\begin{tabular}{|c|c|c|c|}
\hline Variables & Categories & Number & Frequency \\
\hline \multirow{2}{*}{ Dietary counseling during follow-up } & Yes & 465 & 64.5 \\
\hline & No & 256 & 35.5 \\
\hline \multirow{2}{*}{ Admission history of SAM } & Yes & 124 & 17.3 \\
\hline & No & 597 & 82.6 \\
\hline \multirow{2}{*}{ Opportunistic infection (OI at baseline) } & Yes & 258 & 35.8 \\
\hline & No & 453 & 64.2 \\
\hline \multirow{8}{*}{ Types of ART regimen } & D4t-3TC-NVP & 48 & 6.6 \\
\hline & D4t-3TC-EFV & 26 & 3.6 \\
\hline & AZT-3TC-NVP & 293 & 40.6 \\
\hline & AZT-3TC-EFV & 165 & 22.8 \\
\hline & TDF-3TC-EFV & 104 & 14.4 \\
\hline & AZT-3TC-LPV/R & 36 & 4.9 \\
\hline & ABC-3TC-NVP & 25 & 3.5 \\
\hline & ABC-3TC-EFV & 24 & 3.3 \\
\hline \multirow{3}{*}{ ART regimen change } & Yes & 211 & 29.3 \\
\hline & No & 510 & 70.7 \\
\hline & Appropriate & 69 & 71.9 \\
\hline \multirow[t]{3}{*}{ Functional status (age $\leq 5$ years) } & Delay & 15 & 15.6 \\
\hline & Regression & 12 & 12.5 \\
\hline & Working & 488 & 77.9 \\
\hline \multirow{3}{*}{ Developmental history (age $>5$ years) } & Ambulatory & 87 & 13.9 \\
\hline & Bedridden & 51 & 8.15 \\
\hline & Good & 356 & 49.4 \\
\hline \multirow[t]{3}{*}{ Adherence } & Faire & 177 & 24.5 \\
\hline & Poor & 188 & 26.1 \\
\hline & I & 237 & 32.8 \\
\hline \multirow{3}{*}{ WHO clinical stage } & II & 202 & 28.1 \\
\hline & III & 170 & 23.6 \\
\hline & IV & 112 & 15.5 \\
\hline \multirow{2}{*}{ Isoniazid preventive therapy (IPT) } & Yes & 451 & 62.5 \\
\hline & No & 270 & 37.4 \\
\hline \multirow{2}{*}{ Cotrimoxazole preventive therapy } & Yes & 419 & 58.1 \\
\hline & No & 302 & 41.9 \\
\hline \multirow{2}{*}{ CD4 count per $\mathrm{mm}^{3}$} & Below the threshold & 308 & 42.7 \\
\hline & Above threshold & 413 & 57.3 \\
\hline \multirow{2}{*}{ Hemoglobin level } & $\leq 10 \mathrm{~g} / \mathrm{dl}$ & 229 & 31.7 \\
\hline & $>10 \mathrm{~g} / \mathrm{dl}$ & 492 & 68.2 \\
\hline \multirow{8}{*}{ Types of opportunistic other than TB } & Bacterial pneumonia & 79 & 30.6 \\
\hline & Diarrhea & 74 & 28.8 \\
\hline & Meningitis & 9 & 3.6 \\
\hline & PCP & 6 & 2.33 \\
\hline & Skin dermatitis & 7 & 2.7 \\
\hline & Kaposi's sarcoma & 5 & 1.9 \\
\hline & Acute/chronic otitis media & 9 & 3.5 \\
\hline & Others & 3 & 1.18 \\
\hline \multirow{4}{*}{ Duration on ART } & $\leq 36$ months & 223 & 30.93 \\
\hline & $36-72$ months & 295 & 40.92 \\
\hline & $73-180$ months & 203 & 28.16 \\
\hline & On follow-up & 539 & 74.76 \\
\hline \multirow{3}{*}{ Current status of children } & Transferred into other health institution & 68 & 9.43 \\
\hline & Lost to follow-up & 24 & $3.3 \%$ \\
\hline & Died & 90 & 12.48 \\
\hline \multirow{2}{*}{ Maternal PMTC follow-up history } & Yes & 487 & 67.6 \\
\hline & No & 234 & 32.4 \\
\hline MUAC & $\leq 11.5 \mathrm{~cm}$ & 270 & 37.45 \\
\hline MUAC & $>11.5 \mathrm{~cm}$ & 451 & 62.55 \\
\hline Children status during data collection & Died & 87 & 12.07 \\
\hline Cnilaren status during data collection & Survived & 634 & 87.93 \\
\hline & Event & 63 & $8.7 \%$ \\
\hline Incidence of PIB/1B during follow-up & Censored & 658 & $91.2 \%$ \\
\hline
\end{tabular}


TABLE 3: Nutritional status of seropositive children attending ART cares in selected health facility at Benishangul Gumuz regions, 2020 $(n=721)$.

\begin{tabular}{|c|c|c|c|}
\hline Variables & & & Frequency \\
\hline \multirow{3}{*}{ Weight-for-age (WFA) } & Normal growth curve & $\mathrm{WAZ} \geq-2 Z$ score & $491(68.1$ \\
\hline & Moderate underweight & WAZ $-2-3 Z$ score & $144(19.9 \%)$ \\
\hline & Severe underweight & $\mathrm{WAZ} \leq-3 Z$ score & $86(11.9 \%)$ \\
\hline \multirow{3}{*}{ Height-for-age (HFA) } & Normal growth & $\mathrm{HAZ} \geq-2 Z$ score & $428(59.4 \%)$ \\
\hline & Moderate stunting & HAZ -2-3 Z score & $154(21.4 \%)$ \\
\hline & Severe stunting & $\mathrm{HAZ} \leq-3 Z$ score & $139(19.2 \%)$ \\
\hline \multirow{3}{*}{ Weight-for-height (WFH) } & Normal growth curve & $\mathrm{WHZ} \geq-2 Z$ score & $531(73.5 \%)$ \\
\hline & Moderate wasting & WHZ $-2-3 Z$ score & $119(16.6 \%)$ \\
\hline & Severe wasting & $\mathrm{WHZ} \leq-3 Z$ score & $71(9.9 \%)$ \\
\hline \multirow{7}{*}{ SAM admission history by sex, age, and residence $(N=124)$} & \multirow{2}{*}{ Sex } & Male & $65 / 124(52.4 \%)$ \\
\hline & & Female & $59124(47.6 \%)$ \\
\hline & \multirow{3}{*}{ Resident } & Rural & $70 / 124(56.45 \%)$ \\
\hline & & Urban & $54 / 124(43.5 \%)$ \\
\hline & & $\leq 60$ months & $33 / 124(26.6 \%)$ \\
\hline & \multirow[t]{2}{*}{ Age } & $61-120$ months & $42 / 124(33.8 \%)$ \\
\hline & & 121-179 months & $49 / 124(39.5 \%)$ \\
\hline
\end{tabular}

TABLE 4: Clinical presentations of seropositive children before confirmed PTB/TB diagnosed in selected public facility Northwest Ethiopia, 2020 .

\begin{tabular}{lccccccc}
\hline Types of TB $(N=63)$ & Frequency (\%) & Presentation & Cough (\%) & Fever (\%) & Night sweating (\%) & Weight loss (\%) & Hemoptysis (\%) \\
\hline \multirow{2}{*}{ SNPTB } & \multirow{2}{*}{$36(57.2)$} & Present & $31(88.5 \%)$ & $27(72.7)$ & $23(60.6 \%)$ & $23(60.6 \%)$ & $8(15.5 \%)$ \\
& & Absent & $5(15.5 \%)$ & $9(27.7 \%)$ & $13(39.3 \%)$ & $13(39.3 \%)$ & $24(72.3 \%)$ \\
\multirow{2}{*}{ SPPTB } & \multirow{2}{*}{$25(41.2)$} & Present & $18(70.8 \%)$ & $24(95.5 \%)$ & $15(58.3 \%)$ & $14(54.2 \%)$ & $7(25 \%)$ \\
& & Absent & $7(29.2 \%)$ & $1(5.5 \%)$ & $10(42.6 \%)$ & $11(45.8 \%)$ & $18(75 \%)$ \\
EXPTB & \multirow{2}{*}{$2(3.5 \%)$} & Present & $1(50 \%)$ & $2(100)$ & $1(50 \%)$ & $2(100)$ & 0 \\
& & Absent & $1(50 \%)$ & 0 & $1(50 \%)$ & 0 & $2(100)$ \\
\hline
\end{tabular}

SNPTP: smear negative pulmonary TB; SPPTB: smear positive pulmonary TB; EXPTB: extrapulmonary TB.

compared with participant children having normal percentiles (HFA, >-2 Z score). Moreover, hemoglobin levels had a high predictive value for incident TB; indeed, baseline hemoglobin $\leq 10 \mathrm{mg} / \mathrm{dl}$ was four times increase the hazard of developing PTB as compared to children having $\geq 10 \mathrm{mg} / \mathrm{dl}$ (AHR = 4.02: 95\% CI, 2.1-8.1, $P<0.001)$. Similarly, seropositive children who did not address IPT had significant association with PTB occurrence as compared with their peers who have addressed IPT $(\mathrm{AHR}=2.4 ; 95 \% \mathrm{CI}: 1.2 ; 5.1$, $P=0.001$ ) (Table 5).

\section{Discussion}

At the end of the cohort of $721 \mathrm{HIV}$-infected children, 90 children (12.4\%) died, 24 (3.3\%) were lost to follow-up, 68 (15.1\%) were transferred to other health institutions, and 539 $(74.7 \%)$ remained in the follow-up. Moreover, the present study revealed that the crude incidence of $\mathrm{TB}$ among children living with HIV/AIDS was determined as $8.7 \%$ (6.8; 11.04). This report is higher than the finding from Debre Tabor hospital 5.0\% [2], yet it is comparable with finding stated in Arba Minch (7.2\%) [5] and Tanzania (8.5\%) [21] hospitals. This might be due to similarity in the study setting and the association of protective effects of ART. In the contrary, this report is lower than the finding from Zimbabwe (12.01\%) [22] and Yaoundé, Cameroon (61.8\%) [23]. The possible elucidation for the difference may be the size of the study population and the higher burden of tuberculosis in resource-limited settings [1]. In addition, HIV waned the immune system and accelerated viral replication for the depletion of CD4 count [10], which precipitated the new episode of lethal opportunistic infections [24]. This can be reduced by early addressing of CPT and IPT, which is inexpensive and highly effective for reducing loads of endogenous reactivation of latent PTB [25]. Equivalent to this report, however, were seropositive children who missed CPT and had significantly associated with risks of developing PTB. This is consistent with a previous document in Northwest Ethiopia and Gondar hospitals [14, 26]. Moreover, in line with research finding with Northwest Ethiopia, Zaire, and Cameroon [4, 23, 27], our study indicated seropositive children who did not take IPT at baseline had a risk of developing PTB. Consistent with research findings in Northwest Ethiopia [4], concomitant administration of IPT with ART after undertaking in-depth active TB signs, power to have demoted more than ninety-six percent of new TB incidence for children living with HIV. Irrationally, nearly two in five of $(37.45 \%)$ participant children did not take IPT in our study.

Furthermore, result in our research revealed that seropositive children who missed CPT were significantly associated with risks of developing PTB. This discovery is comparable with the previous description in Gondar [28] and Adam hospitals [12]. Cotrimoxazole prophylaxis is safe, 
TABLE 5: Bivariable and multivariable Cox-proportional hazard analysis for predictors of PTB among children who received ART in a selected public health facility in Northwest Ethiopia $(N=721)$.

\begin{tabular}{|c|c|c|c|c|}
\hline Variables & Categories & CHR (95\% CI) & AHR & $P$ value \\
\hline \multirow{3}{*}{ Sex } & Male & $1.8(1.1,3.0)$ & $1.5(0.83 ; 2.7)$ & 0.11 \\
\hline & Female & 1 & 1 & \\
\hline & $\leq 5$ years & 1 & 1 & \\
\hline \multirow[t]{2}{*}{ Age } & $6-10$ years & $1.3(0.85,1.7)$ & $1.7(0.8 ; 4.2)$ & 0.27 \\
\hline & $11-15$ years & $1.9(1.2,3.8)$ & $1.5(0.64 ; 3.5)$ & 0.34 \\
\hline \multirow{3}{*}{ Residence } & Rural & $3.4(2.5,9.7)$ & $1.7(0.76 ; 3.8)$ & 0.19 \\
\hline & Urban & 1 & 1 & \\
\hline & $\leq 2$ & 1 & 1 & \\
\hline \multirow[t]{2}{*}{ Family size } & $3-5$ & $2.5(1.2 ; 4.5)$ & $2.1(0.9 ; 13.7)$ & 0.05 \\
\hline & $\geq 6$ & $1.3(0.4 ; 4.8)$ & $2.3(0.94 ; 9.2)$ & 0.31 \\
\hline \multirow{2}{*}{ Disclosure status } & Yes & $2.5(2.2 ; 7.5)$ & $1.2(0.6 ; 2.2)$ & 0.42 \\
\hline & No & 1 & 1 & \\
\hline \multirow{2}{*}{ IP } & Given & 1 & 1 & \\
\hline & Not given & $5.6(2.1,8.3)$ & $2.4(1.2 ; 5.1)^{*}$ & $0.01^{*}$ \\
\hline \multirow{3}{*}{$\mathrm{CPT}$} & Given & 1 & 1 & \\
\hline & Not given & $3.7(2.8 ; 7.8)$ & $2.5(1.4-4.7)^{*}$ & $0.02^{*}$ \\
\hline & Good & 1 & 1 & \\
\hline \multirow[t]{3}{*}{ ART drug adherence } & Fair & $2.1(1.7 ; 4.1)$ & $1.8(0.97-2.4)$ & 0.31 \\
\hline & Poor & $3.1(2.05 ; 6.3)$ & $1.2(0.68-2.2)$ & 0.11 \\
\hline & HFA $\geq-2 Z$ score & 1 & 1 & \\
\hline \multirow{2}{*}{ Height-for-age (HFA) } & HFA -2-3 $Z$ score & $2.1(1.5 ; 2.8)$ & $1.2(0.8-2.7)$ & 0.17 \\
\hline & HFA $\leq-3 Z$ score & $3.9(3.8 ; 5.1)$ & $2.9(1.2-7.8)^{*}$ & $0.03^{*}$ \\
\hline \multirow{2}{*}{ WHO clinical stages } & Stage I \& II & 1 & 1 & \\
\hline & Stage III \& IV & $5.1(4.9 ; 6.4)$ & $1.8(0.8-2.5)$ & 0.12 \\
\hline \multirow{2}{*}{ Levels of hemoglobin } & $>10 \mathrm{mg} / \mathrm{dl}$ & 1 & 1 & \\
\hline & $\leq 10 \mathrm{mg} / \mathrm{dl}$ & $9.6(5.13 ; 18.0)$ & 4. $(2.1 ; 8.1)$ & $0.01^{*}$ \\
\hline \multirow{3}{*}{ Baseline MUAC } & $\leq 11.5 \mathrm{~cm}$ & $2.4(1.5 ; 3.9)$ & $1.7(0.89 ; 2.5)$ & 0.11 \\
\hline & $>11.5 \mathrm{~cm}$ & 1 & 1 & \\
\hline & $\mathrm{WAZ} \leq-3 Z$ score & $2.8(1.5 ; 3.3)$ & $1.7(0.6 ; 4.59)$ & 0.26 \\
\hline \multirow{3}{*}{ Weight-for-height (WFH) } & WAZ $-2-3 Z$ score & $2.6(1.92 ; 2.8)$ & $1.61(0.91 ; 2.85)$ & 0.10 \\
\hline & $\mathrm{WAZ} \geq-2 Z$ score & 1 & 1 & \\
\hline & $\leq 36$ months & 1 & 1 & \\
\hline \multirow[t]{2}{*}{ Times of follow-up } & $36-72$ months & $1.9(0.76 ; 4.8)$ & $0.86(0.29 ; 2.6)$ & 0.80 \\
\hline & $73-180$ months & $2.4(1.99 ; 8.53)$ & $1.5(0.7 ; 3.02)$ & 0.36 \\
\hline \multirow{2}{*}{ SAM admission history (SAM) } & Yes & $2.4(1.9 ; 6.3)$ & $1.3(0.68 ; 2.5)$ & 0.69 \\
\hline & No & 1 & 1 & \\
\hline \multirow{2}{*}{$\mathrm{CD} 4 / \mathrm{mm}^{3}$ count } & Below threshold & $2.2(1.7 ; 4.1)$ & $1.4(0.82 ; 5.1)^{*}$ & 0.21 \\
\hline & Above threshold & 1 & 1 & \\
\hline
\end{tabular}

inexpensive, and highly effective in reducing morbidity and mortality among HIV-infected infants and children. The World Health Organization (WHO) recommends that all HIV-exposed infants be started on cotrimoxazole prophylaxis at four to six weeks of age, to provide adequate prevention against early opportunistic infections (OIs). This is particularly critical for HIV-infected infants. Data from a randomized clinical trial conducted in Zambia demonstrated the effectiveness of cotrimoxazole prophylaxis in reducing mortality and morbidity among HIV-infected children, despite high levels of bacterial resistance $[6,10,14]$. One of the main challenges countries must address to scale up cotrimoxazole prophylaxis is the absence of mechanisms to systematically identify and follow up HIV-exposed infants at and after birth. If HIV-infected children are to be identified early in the course of their disease-a prerequisite for receiving cotrimoxazole prophylaxis and early ART-systems need to be in place to ensure that health workers consider the possibility of HIV infection in infants at birth and at all clinics or other health encounters thereafter $[1,4,10,29]$. Our finding also indicated that the median $( \pm \mathrm{IQR})$ time of $\mathrm{TB}$ reported and the overall $\mathrm{TB}$ incidence (IDR) were determined as $17.8( \pm 11)$ months and 5.86 per 100 child years (95\% CI: $4.58,7.5)$, respectively. The human immune deficiency virus (HIV) is the strongest risk factor for endogenous reactivation of pulmonary tuberculosis (PTB) through target reduction of CD4 and T-lymphocytes, with rapid bacilli reactivation after children are already exposed to infections [14].

Our study also indicated that participant children at baseline being nutritionally severely stunted were independently associated with PTB occurrence as compared with those who have WHO curve $\geq-2 Z$ score. This is similar to finding s in Adama [30], Tanzania [31], and Uganda and Zimbabwe hospitals [32]. This might be due to HIV infection increasing nutrient mal-absorption due to metabolic alterations that culminate in weight loss and stunting with time leading to early exposure for 
opportunistic infections [11]. Comparably, the existence of rapid viral replication consumed body energy and creates an arena for developing deadly opportunistic infections $[33,34]$. This finding also showed that children having hemoglobin $\leq 10 \mathrm{mg} / \mathrm{dl}$ were independently related to HIV-associated PTB occurrence as compared with HIV-infected countergroups. This is in line with the study finding in Adama hospital [30], Gondar hospital [12], Northern Ethiopia [28], Dar es Salaam, Tanzania [31], and England [35]. This is due to hemoglobin levels having a high predictive value for tuberculosis incidence [36].

4.1. Limitation of the Study. The retrospective nature of this study is one of the limitations of this study. Due to this, some of the clinically important predictor variables that have been independently associated with the incidence of TB occurrence in other studies, like the educational status of children and economic status of the family, were not included in these studies.

\section{Conclusion}

We found a high burden of pulmonary TB among children living with HIV/AIDS as compared with previous reports in Ethiopia. Cases at baseline not taking IPT and CPT, being severely stunted, and having low hemoglobin $(\leq 10 \mathrm{mg} / \mathrm{dl})$ levels were found to be at higher risk to PTB occurrence. Besides, intensified screening for provisions of isoniazid preventive therapy to children living with HIV/AIDS is highly recommended.

\section{Abbreviations}

$\begin{array}{ll}\text { TB: } & \text { Tuberculosis } \\ \text { CPT: } & \text { Cotrimoxazole preventive therapy } \\ \text { Hgb: } & \text { Hemoglobin } \\ \text { IPT: } & \text { Isoniazid preventive therapy } \\ \text { AHR: } & \text { Adjusted hazard ratio } \\ \text { CHR: } & \text { Crude hazard ratio } \\ \text { FMOH: } & \text { Ethiopian Federal Ministry of Health } \\ \text { MUAC: } & \text { Midupper arm circumference } \\ \text { PLWHIV: } & \text { People living with HIV } \\ \text { WFH: } & \text { Weight-for-height } \\ \text { WFA: } & \text { Weight-for-age } \\ \text { HFA: } & \text { Height-for-age } \\ \text { SAM: } & \text { Severe acute malnutrition } \\ \text { WFH: } & \text { Weight-for-height } \\ \text { SD: } & \text { Standard deviation } \\ \text { IQR: } & \text { Interquartile range. }\end{array}$

\section{Data Availability}

The data sets of this research are available from the main author on reasonable request.

\section{Ethical Approval}

Ethical clearance and ethical approval were obtained from the research institute review board (IRB) of Debre Markose
University with reference (refill no.: DMU IRB-984/118/13). A formal letter was submitted to all three hospitals for permission to be done.

\section{Consent}

Debra Markose University waived consent from caregivers; in addition, the National Research and Ethical Review Guide waived consent for secondary files.

\section{Disclosure}

The funders had no role in this study except giving stay for their students on the time of research.

\section{Conflicts of Interest}

All authors declare that they have no conflicts of interest in this research.

\section{Authors' Contributions}

FK, HT, MM, DJ, and AA equally contributed to the work reported in conception, study design, execution, analysis, and interpretation, and writing the manuscript, and finally all authors approved for final submission.

\section{Acknowledgments}

The authors thank data collectors and supervisors in all health institutions for their unreserved comment for reaching this step. The study material and financial support were received from Debre Markose University's postgraduate school as MPH, student research support fund.

\section{References}

[1] WHO, FMOH: Ethiopia-National Guidelines for TB, DR-TB, and Leprosy in Ethiopia, WHO, Geneva, Switzerland, Sixth edition, 2017.

[2] T. Kiros, E. Dejen, M. Tiruneh et al., "Magnitude and associated factors of pulmonary tuberculosis among HIV/AIDS patients attending antiretroviral therapy clinic at Debre tabor specialized hospital, northwest Ethiopia," HIV AIDS (Auckl), vol. 12, pp. 849-858, 2020.

[3] Y. Wu, Y. Yang, H. Wei et al., "Mortality predictors among patients with HIV-associated pulmonary tuberculosis in Northeast China: a retrospective cohort analysis," Journal of Medical Virology, vol. 93, no. 8, pp. 4901-4907, 2021.

[4] F. Kebede, B. Kebede, T. Kebede, and M. Agmasu, "Effect of isoniazid preventive therapy on the incidence of tuberculosis among seropositive children attending HIV/AIDS care in two general hospitals, northwest Ethiopia, 2021," Journal of Tropical Medicine, vol. 2021, Article ID 9996953, 9 pages, 2021.

[5] M. Mama, A. Tesfa, H. Mohammed, and E. Erbo, "Prevalence of pulmonary tuberculosis and associated factors among HIV positive patients attending antiretroviral therapy clinic at Arba minch general hospital, southern Ethiopia," The Open Microbiology Journal, vol. 12, pp. 163-171, 2018.

[6] WHO, Global Tuberculosis Report 2020, WHO, Geneva, Switzerland, 2020. 
[7] C. Marotta, M. Abdu, Y. Ali et al., "Determinant factors for the occurrence of tuberculosis after initiation of antiretroviral treatment among adult patients living with HIV at Dessie referral hospital, South Wollo, Northeast Ethiopia, 2020. a case-control study," PLoS One, vol. 16, no. 3, Article ID e0248490, 2021.

[8] WHO, Global Tuberculosis Report 2019, WHO, Geneva, Switzerland, 2019.

[9] Z. Dawit, S. Abebe, S. Dessu, M. Mesele, S. Sahile, and D. Ajema, "Incidence and predictors of mortality among children co-infected with tuberculosis and human immunodeficiency virus at public hospitals in Southern Ethiopia," PLoS One, vol. 16, no. 6, Article ID e0253449, 2021.

[10] WHO, FMOH: Nationalconsolidated Guidelines For Comprehensive HIV Prevention, Care, and Treatment, WHO, Geneva, Switzerland, 2018.

[11] WHO, Ethiopian FMOH: National Guidelines For Comprehensive HIV Prevention, Care, and Treatment, WHO, Geneva, Switzerland, 2017.

[12] S. Ayalaw and A. A. Adane, "Incidence and predictors of tuberculosis among HIV Positive children at university of Gondar referral hospital, Northwest Ethiopia: a retrospective follow-up study," International Scholarly Research Notices, vol. 2015, Article ID 307810, 6 pages, 2015.

[13] F. Kebede, N. Eticha, N. Eticha et al., "Predictors for a cure rate of severe acute malnutrition 6-59 month children in stabilizing center at pawe general hospital, northwest Ethiopia: retrospective cohort study," International Journal of Child Health and Nutrition, vol. 10, pp. 34-43, 2021.

[14] F. Kebede, T. Kebede, B. Kebede et al., "Time to develop and predictors for incidence of tuberculosis among children receiving antiretroviral therapy," Tuberculosis Research and Treatment, vol. 2021, Article ID 6686019, 9 pages, 2021.

[15] D. F. Moore and D. F. Moore, Applied Survival Analysis Using $R$, Springer Nature, Berlin, Germany, 2015.

[16] World Health Organization (WHO), Updates on the Management of Severe Acute Malnutrition in Infants and Children, World Health Organization, Geneva, Switzerland, 2013.

[17] WHO (World Health Organization), Guideline Updates on the Management of Severe Acute Malnutrition in Infants and Children, WHO, Geneva, Switzerland, 2013.

[18] A. Alebel, F. Wagnew, C. Tesema, G. D. Kibret, P. Petrucka, and S. Eshite, "Effects of undernutrition on survival of human immunodeficiency virus positive children on antiretroviral therapy," Italian Journal of Pediatrics, vol. 44, no. 1, p. 29, 2018.

[19] B. B. Abate, T. G. Aragie, and G. Tesfaw, "Magnitude of underweight, wasting and stunting among HIV positive children in East Africa: a systematic review and meta-analysis," PLoS One, vol. 15, no. 9, Article ID e0238403, 2020.

[20] WHO, Guidelines for Paediatric HIV/AIDS Care and Treatment in Ethiopia, Federal HIV/AIDS Prevention and Control Office Federal Ministry of Health, WHO, Geneva, Switzerland, 2007.

[21] B. J. Ngowi, S. G. Mfinanga, J. N. Bruun, and O. Morkve, "Pulmonary tuberculosis among people living with HIV/ AIDS attending care and treatment in rural northern Tanzania," BMC Public Health, vol. 8, no. 1, p. 341, 2008.

[22] S. Swindells, L. Komarow, K. P. Cain et al., "Screening for pulmonary tuberculosis in HIV-infected individuals: AIDS clinical trials group protocol A5253," International Journal of Tuberculosis \& Lung Disease, vol. 17, no. 4, pp. 532-539, 2013.

[23] N. Kinkela, M. Ntoto, D. Roger, and C. David, "Pulmonary tuberculosis in children with hiv infection from symptoms todiagnosis and treatment in a pediatriccenter," Journal of HIV \& Retro Virus, vol. 2, no. 1, p. 6, 2014.

[24] B. Tulu, E. Amsalu, Y. Zenebe et al., "Diabetes mellitus and HIV infection among active tuberculosis patients in Northwest Ethiopia: health facility-based cross-sectional study," Tropical Medicine and Health, vol. 49, no. 1, p. 68, 2021.

[25] N. Gopalan, P. Chandrasekaran, S. Swaminathan, and S. Tripathy, "Current trends and intricacies in the management of HIV-associated pulmonary tuberculosis," AIDS Research and Therapy, vol. 13, no. 1, p. 34, 2016.

[26] K. A. Atalell and D. T. Ekubagewargies, "Survival and predictors of mortality among children co-infected with tuberculosis and human immunodeficiency virus at university of Gondar comprehensive specialized hospital, Northwest Ethiopia. a retrospective follow-up study," PLoS One, vol. 13, no. 5, Article ID e0197145, 2018.

[27] J. Joseph, "PULMONARY tuberculosis IN HIV-infected patients IN zaire A controlled trial of treatment for either 6 or 12 months," New England Journal of Medicine, 2021.

[28] Y. M. Alemu, G. Andargie, and E. Gebeye, "High incidence of tuberculosis in the absence of isoniazid and cotrimoxazole preventive therapy in children living with HIV in northern Ethiopia: a retrospective follow-up study," PLoS One, vol. 11, no. 4, Article ID e0152941, 2016.

[29] G. Ferrara, M. Murray, K. Winthrop et al., "Risk factors associated with pulmonary tuberculosis," Current Opinion in Pulmonary Medicine, vol. 18, no. 3, pp. 233-240, 2012.

[30] M. T. Beshir, A. H. Beyene, K. G Tlaye, and T. M. Demelew, "Incidence and predictors of tuberculosis among HIV-positive children at Adama referral hospital and Medical College, Oromia, Ethiopia: a retrospective follow-up study," Epidemiology and Health, vol. 41, Article ID e2019028, 2019.

[31] L. Nan and S. Donna, "Incident tuberculosis and risk factors among HIV-infected children in Dar Es Salaam, Tanzania," AIDS, vol. 27, no. 8, 2016.

[32] A. M. Crook, "Tuberculosis incidence is high in HIV-infected African children but is reduced by co-trimoxazole and time on antiretroviral therapy," BMC Medicine, vol. 14, no. 1, 2016.

[33] F. Kebede, B. Kebede, T. Kebede, and M. Agmasu, "Effect of isoniazid preventive therapy on the incidence of tuberculosis among seropositive children attending HIV/AIDS care in two general hospitals, Northwest Ethiopia," Journal of Tropical Medicine, vol. 2021, Article ID 9996953, 9 pages, 2021.

[34] World Health Organizations, Antiretroviral Therapy for HIV Infection in Infants and Children: Towards Universal Access, WHO Library Cataloguing-in-Publication Data, Geneva, Switzerland, 2010 .

[35] A. T. Brennan, R. Bonawitz, K. Schnippel et al., "Incident tuberculosis in HIV-positive children, adolescents and adults on antiretroviral therapy in South Africa," International Journal of Tuberculosis \& Lung Disease, vol. 20, no. 8, pp. 1040-1045, 2016.

[36] A. Mocroft, O. Kirk, S. E. Barton et al., "Anaemia is an independent predictive marker for clinical prognosis in HIVinfected patients from across Europe," Anemia and Clinical Prognosis Mocro, vol. 13, no. 8, pp. 943-950, 1999. 